\title{
Gas Liquid Chromatographic Analysis of Treated Biocontrol Agents Mint Oil
}

\author{
Islam M. H. Rizk" ${ }^{1 *}$, Ibrahim A. Ibrahim², Mohamed M. Ammar and Ibrahim E. Mousa1 \\ ${ }^{1}$ Environmental Biotechnology Department, Genetic Engineering and Biotechnology Research Institute, \\ University of Sadat City, Egypt.
}

${ }^{2}$ Plant Biotechnology Department, Genetics Engineering and Biotechnology Research Institute, University of Sadat City, Egypt.

${ }^{3}$ Agricultural Botany Department, Faculty of Agriculture, Minufiya University, Egypt.

Corresponding author: islam rizk2@yahoo.com.

\begin{abstract}
Gas liquid chromatographic analysis of spearmint oil revealed that the oil of this species has 13 different derivatives. The untreated control plants expressed all of them except phellandrene, which present in the bioagents treatment; the later showed the absence oflimonene and menthone. The least concentration value was noticed with caryophellene (1.072\%). Gas liquid chromatographic analysis of peppermint oil expressed different 13 derivatives. B-purine was detected in this species but not in spearmint one. Menthol showed the highest concentrations were 10.333 and 10.255 respectively. The least values were recorded with Limonene (1.804 and $0.325 \%$ ) for the control and bioagent treated plants respectively.
\end{abstract}

Keywords: Gas Liquid Chromatographic, spearmint oil, peppermint oil.

\section{INTRODUCTION}

Medicinally, the various mints have been used worldwide for centuries as a cure or relief for numerous ailments from flatulence and digestive complaints to fevers (Bove, 1996 and Hoffman, 1996). Peppermint is taken internally as a tea, tincture, oil or extract and applied externally as a rub or liniment. Herbalists consider peppermint as astringent, antiseptic, antipruritic, antispasmodic, antiemetic, carminative, diaphoretic, mild bitter, analgesic, anticatarrhal

Antimicrobial, rubefacient, stimulant and emmenagogue (Bove, 1996 and Hoffman, 1996). It has traditionally been used to treat a variety of digestive complaints such as colic in infants, flatulence, diarrhea, indigestion, nausea and vomiting, morning sickness and anorexia and as a spasmolytic to reduce gas and cramping. Also, it is currently used to treat irritable bowel syndrome, Crohn's disease, ulcerative colitis, gallbladder and biliary tract disorders and liver complains (Blumenthal, 1998 and Fleming, 1998). Peppermint oil is used to relieve menstrual cramps, and externally for neuralgia, myalgia, headaches, migraines and chicken pox (Bove 1996 and Blumenthal, 1998).

Essential oils from some Mentha
species were obtained by Drying hydro
distillation and analysed by GC-MS: numerous
compounds were identified. The most
abundant were menthone, isomenthone,


menthol, carvone, piperitone oxide, Dlimonene and eucalyptol. Chemometric similarity measures and principal component analysis were calculated, allowing comparisons based on secondary metabolite content (Hawryłet. al., 2015).

The study is aimed to in Vitro studies to evaluate the efficacy of different concentrations of mint oil as a fungicide in Petri dishes. Extraction of the mint oil and comparison between the oil components using gas chromatography (GC) technique.

\section{EXPERIMENTAL}

\section{Separation of mint oil}

The fresh mint plants were cut into small pieces, which transferred into a mint tube. Mint tubes were then hauled from the field, two at a time, back to the mint distillery where the oil will be extracted. Steam works its way through the mint plants vaporizing the oil from leaves and taking it to the top of the tube. The oil and water vapor then exits the tub and flows to the condenser tanks, which are full of cool water. The vapor runs through a series of tubes called the condenser and is eventually turned back into a liquid. The liquid comes out bottom of the condenser and into a tank called the separator. In the separator the oil floats to the top because it is lighter than the water maker comparison between the oil compounds was achieved using gas chromatography (GC) technique.

Separation conditions of essential oil instrument:

Gas Liquid Chromato-graphy/ Unicam PRO- GC.

COLUMN: 3\% OV-17 (Methyl phenyl Silicone) on ChromosorbWHP

Mesh: 100-120; Dimensions: $1.5 \times 4 \mathrm{~mm}$; Temperature Programing (InitialTemp. $70^{\circ} \mathrm{C}$; Initial Time. 5min; Rate $8^{\circ} \mathrm{C} / \mathrm{min}$; Final Temp. $200^{\circ} \mathrm{C}$; Final Time 40min; Injector $250 \stackrel{\circ}{\circ}$; Detector $300 \stackrel{\circ}{ }$. Gases Flow Rate $\left(\mathrm{N}_{2} 30 \mathrm{ml} / \mathrm{min} ; \mathrm{H}_{2} \quad 33 \mathrm{ml} /\right.$ $\min$; Air $330 \mathrm{ml} / \mathrm{min}$ ).

Effect of mint oil on the growth of pathogenic fungi

Different concentrations of mint oil i.e., $1.5 \%, 3 \%$ and $4.5 \%$ were prepared in PDA medium either Fusarium oxysporum or Rhizocotinia solani(B) $(6 \mathrm{~mm}$ in diameter) was put in the middle of each Petri dish. Control dishes included PDA medium only and three dishes were used as replicates for each treatment. All dishes were incubated at $25^{\circ} \mathrm{C}$ until the control dish was full with each fungal growth.

\section{RESULTS}

\section{The fungicidal effect of mint oil.}

Mint oil at the concentrations of 1.5 , 3 and $4.5 \%$ was tested against either Fusarium oxysporum or Rhizoctonia solani(B) on PDA medium. Results in

Table (1) and Figures (1\&2) clear that mint oil at all tested concentrations significantly reduced the growth of both pathogens. Growth reduction of $F$. oxysporum was increased from $51 \%$ to $86 \%$ respectively at 1.5 and $4.5 \%$ mint oil concentrations. Reduction of $R$. solani(B) growth ranged from 63 and $83 \%$

Gas liquid chromatographic analysis of spearmint oil. Table (2) clear that the oil of this species has 13 different derivatives. The untreated control plants 
expressed all of them except Phellandrene; which present in the biofertilized treatment. The later showed the absence of Limonene and Menthone. Both Menthone and Isomentone expressed the highest concentrations (12.132 and $10.962 \%$ of spearmint control oil. Menthol, Limonene and 1.8- cineol respectively resulted 9.353, 9.263 and $9.115 \%$ concentrations. The least concentration values were noticed with Caryophellene (1.072\%) and Pulegone (1.809 $\%)$.

\section{Effect of bioagent on oil content.}

Biofertilizer treatment resulted so high Menthol (40.906 \%) and Carvone (20.145\%). The least component values $(0.210$ and 0.935 \%) were respectively recorded with Caryophellene and Pulegone derivatives.
On the other hand; peppermint oil expressed different 13 derivatives Table (3). áPinene and $B$. pinene were detected in all species. Menthol showed the highest concentrations (20.087 and $15.368 \%)$ respectively for control and biofertilized peppermint plants. This was followed by 1.8 cineole (9.724 and $11.782 \%)$, in the same respect.

Phellandrene concentrations were 10.333 and $10.255 \%$ respectively. The least values were recorded with Limonene (1.804 and $0.325 \%$ ) for the control and biofertilized plants respectively. These percentages were 3.853 and $2.481 \%$ for Caryophyllene, in the same respect.

Table (1): Effect of different concentrations of mint oil on the mycelial growth diameter (cm) of Fusarium oxysporum and Rhizoctonia solani(B) (cm).

\begin{tabular}{|c|c|c|c|c|}
\hline Mint oil \% & $\begin{array}{c}\text { Fusarium } \\
\text { oxysporum }\end{array}$ & $\mathbf{R} \%$ & $\begin{array}{c}\text { Rhizocotinia } \\
\text { solani (B) }\end{array}$ & ${ }^{{ }^{*} \mathbf{R} \%}$ \\
\hline 1.5 & 4.25 & 51 & 3.22 & 63 \\
\hline 3.0 & 2.98 & 66 & 2.97 & 66 \\
\hline 4.5 & 1.18 & 86 & 1.43 & 83 \\
\hline Control & 8.67 & & 8.63 & \\
\hline L.S.D at $5 \%$ & 0.24 & & 0.35 & \\
\hline L.S.D at $1 \%$ & 0.35 & & 0.51 & \\
\hline
\end{tabular}

Colony reduction $\%$ compared with control. $\%: \mathrm{R}^{*}$ 


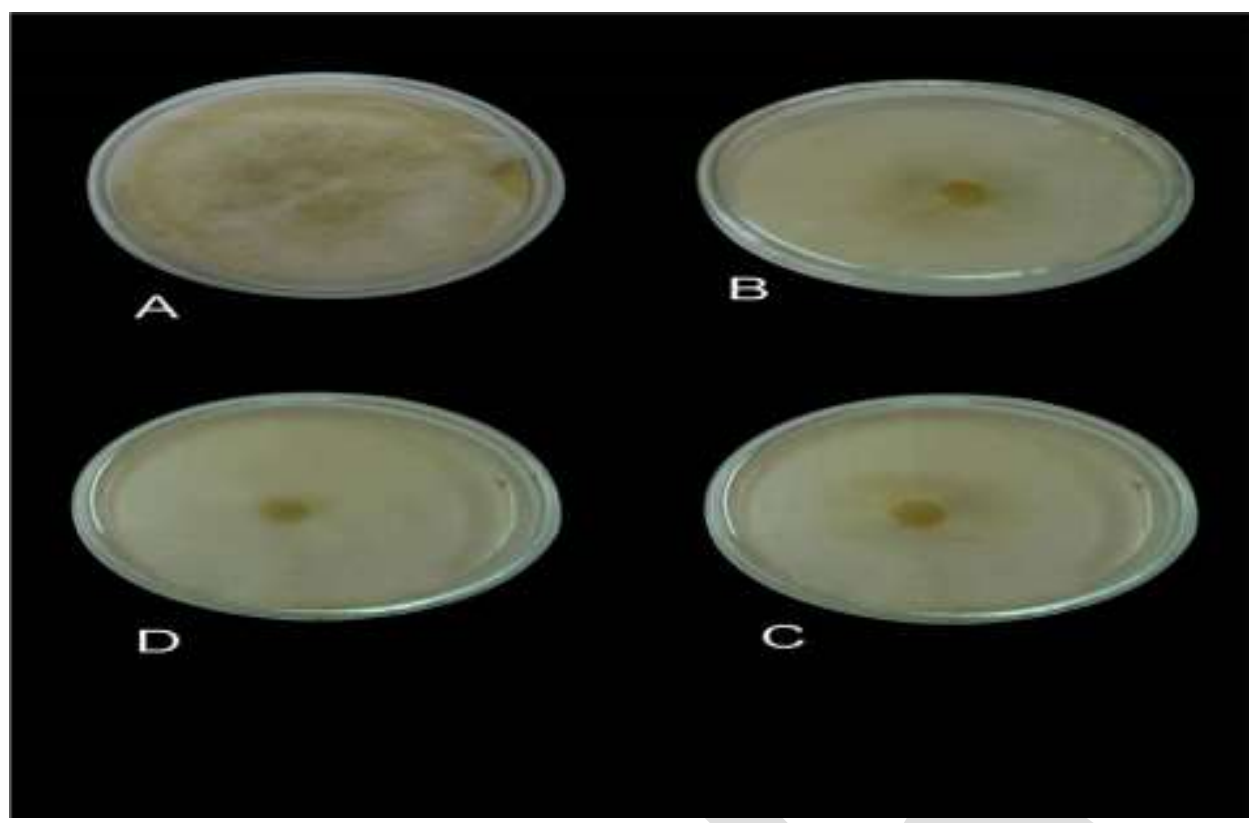

Figure (1): Effect of different concentrations of mint oil in PDA medium on the growth of Fusarium oxysporm
A. 0 (control)
B. $1.5 \%$
C. $3 \%$
D. $4.5 \%$

Notice: there is no growth at all at the concentration of $4.5 \%$ mint oil.

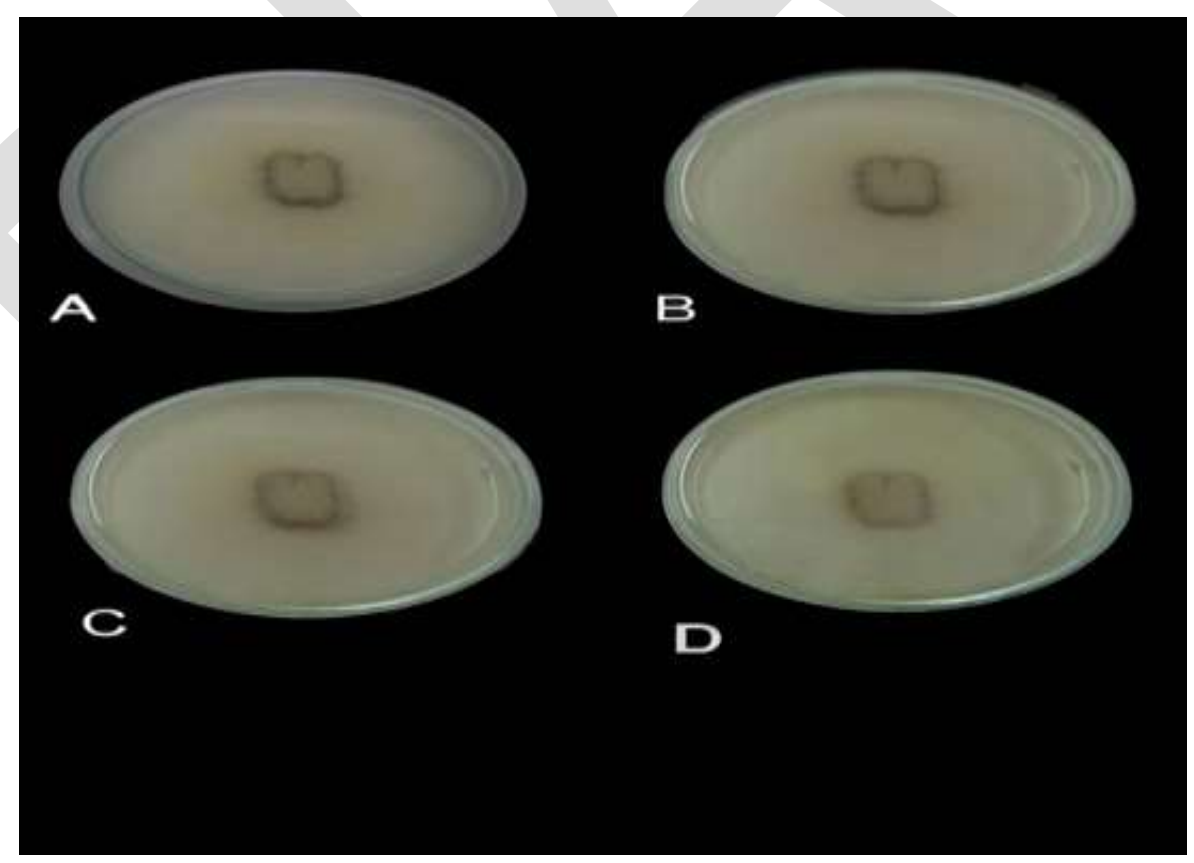

Figure (2): Effect of different concentrations of mint oil in PDA medium on the growth of Rhizocotonia solani $(B)$.
A. 0 (control)
B. $1.5 \%$
C. $3 \%$
D. $4.5 \%$

Notice: that there is no growth at all at the concentration of $4.5 \%$ mint oil 
Table (2): Gas chromatographic analysis of spearmint oil extracted from the untreated and plants treated with bioagents (Trichoderma harzianum + Bacillus subtalus 11 against Rhizocotonia solani $(B)$ ).

\begin{tabular}{|l|l|l|c|l|l|l|}
\hline \multirow{2}{*}{ Component } & \multicolumn{4}{l|}{ Untreated control } & \multicolumn{2}{l|}{ Biologically fertilized } \\
\cline { 2 - 7 } & RT(min.) & Height & Conc.\% & RT(min.) & Height & Conc.\% \\
\hline á- Pinene & 4.283 & 34.069 & 1.314 & 4.050 & 4.263 & 0.783 \\
\hline$\beta$ - Pinene & 5.033 & 4.567 & 0.216 & 5.933 & 8.123 & 2.020 \\
\hline $1.8-$ Cineole & 8.400 & 107.015 & 9.115 & 8.650 & 37.712 & 7.728 \\
Limonene & 9.017 & 107.032 & 9.263 & -- & -- & -- \\
Pulegone & 10.300 & 41.599 & 1.809 & 10.300 & 4.323 & 0.935 \\
Menthol & 13.283 & 107.155 & 9.353 & 13.183 & 107.319 & 40.906 \\
Iso menthol & 15.333 & 98.979 & 6.458 & 14.267 & 3.453 & 1.158 \\
Menthone & 14.400 & 107.188 & 12.132 & -- & -- & -- \\
Isomenthone & 16.550 & 107.250 & 10.962 & 15.117 & 4.801 & 1.141 \\
Menthylacetate & 15.800 & 107.228 & 4.958 & 15.600 & 51.569 & 8.13120 .145 \\
Carvone & 17.633 & 102.868 & 5.569 & 15.950 & 95.058 & 0.210 \\
Caryophellene & 18.717 & 28.446 & 1.072 & 19.067 & 1.505 & 5.811 \\
Phellandrene & -- & -- & -- & 7.933 & 28.149 & \\
\hline
\end{tabular}

Table (3): Gas chromatographic analysis of peppermint oil extracted from the untreated and plants treated with bioagents (Trichoderma harzianum +Bacillus subtalus 11 against Rhizocotonia solani (B)).

\begin{tabular}{|l|l|l|l|l|l|l|}
\hline \multirow{2}{*}{ Component } & \multicolumn{3}{|c|}{ Untreated control } & \multicolumn{3}{c|}{ Biologically fertilized } \\
\cline { 2 - 7 } & RT(min.) & Height & Conc.\% & RT(min.) & Height & \multicolumn{1}{|c|}{ Conc.\% } \\
\hline \multicolumn{1}{|c|}{ á- Pinene } & 3.950 & 103.840 & 4.750 & 3.950 & 64.793 & 2.866 \\
\hline Phellandrene & 8.017 & 100.528 & 10.333 & 7.983 & 106.036 & 10.255 \\
1.8- Cineole & 8.667 & 99.838 & 9.724 & 8.650 & 106.156 & 11.782 \\
Limonene & 9.000 & 39.048 & 1.804 & 9.583 & 8.471 & 0.3255 .866 \\
Pulegone & 10.050 & 98.370 & 6.627 & 9.967 & 106.393 & 15.368 \\
Menthol & 13.650 & 88.060 & 20.087 & 13.433 & 107.019 & 4.287 \\
Menthone & 13.883 & 85.270 & 4.214 & 13.833 & 53.148 & 5.270 \\
Iso menthol & 14.933 & 79.650 & 4.363 & 14.833 & 68.697 & 4.5735 .969 \\
Menthylacetate & 15.633 & 72.416 & 5.962 & 15.567 & 107.404 & 3.557 \\
Isomenthone & 15.917 & 69.488 & 3.587 & 15.867 & 107.458 & 2.481 \\
Carvone & 17.367 & 98.730 & 3.961 & 17.317 & 80.605 & \\
Caryophellene & 18.733 & 102.951 & 3.853 & 18.733 & 60.294 & \\
\hline
\end{tabular}




\section{DISCUSSION}

The highest antioxidant properties of essential oils might be related to its phenolic contents like phenolic acids, rosmarinic acid and polyphenols as reported in a previous study (Mimica-Dukic et al., 1998). Therefore, the reason of the poor activity of these essential oils, probably, is due to its lack or low amount of phenolic contents; synergistic or antagonistic effect of its components (Candan et al., 2003). It has earlier been reported that plant phenols can behave as ROS (Reactive Oxygen Species) scavengers, metal chelators and enzyme modulators and prevent lipid peroxidation (Rodrigo and Bosco, 2006). The results show a difference in the contents of the essential oil of two mint species, out of polyphenol, flavonoides and tannins. $M$. piperita is richest in these compounds and shows stronger antioxidant activity with respect to M. spicata. The present study confirmed the antioxidant activity of two mint species.

Mint oil at the concentrations of $1.5,3.0$ and $4.5 \%$ of PDA medium significantly reduced the growth of $F$. oxysporum and Rhizoctoniasolani(B); as compared with control. The fungicidal effect of mint oil was also reported by Imai et al., (2001). Application of suitable concentration of mint oil to the seeds or seedlings could be useful and

safe method to control soil borne pathogens as reported by Pereira et al., (2006).

Gas liquid chromatographic analysis proved that spearmint and peppermint oils had 11 and 12 different derivatives. $\beta$-pinene was detected in peppermint oil but not of the other species. On the other hand; application of the biocontrol agents to the soil of spearmint species led to the presence of Phellandrene and absence of both Limonene and Menthone these treatments showed so high Mentol and Carvone in spearmint oil. Menthol also showed the highest concentration derivative of peppermint oil; both for the untreated and bioagent treated samples.

Gas liquid chromatographic analysis of peppermint oil expressed different 13 derivatives. B-pinene was detected in this species but not in spearmint one. Menthol showed the highest concentration (20.087 and 15.368) respectively for control and biofertilized peppermint plants which followed by 1.8 cineole ( 9.724 and $11.782 \%$ ) in the same respect and Phellandrene concentrations were 10.333 and 10.255 respectively. The least values were recorded with Limonene (1.804 and $0.325 \%)$ for the control and bioagent treated plants respectively

\section{CONCLUSION}

Mint species are used widely throughout the world as an important medicinal plant. Their oils are one of the most popular and widely used essential oils, mostly because of its main components such as menthol and carvone. Menthol showed the highest concentration ( 20.087 and 15.368) respectively for control and biofertilized peppermint plants which followed by 1.8 cineole ( 9.724 and $11.782 \%$ ) in the same respect and Phellandrene concentrations were 10.333 and 10.255 respectively. The least values were recorded with Limonene (1.804 and $0.325 \%)$ for the control and bioagent treated plants respectively. 


\section{REFERENCES}

Blumenthal, M., (1998). The complete

German

Commission

Monographs: therapeutic guide

to herbal medicines. Austin:

American Botanical Council.

Bove, M., (1996). An encyclopedia of natural healing for children and infants. New Canaan, CT: Keats Publishing. Inc.

Candan, F., M. Unlu, B. Tepe, D. Daferera, M. Polissiou, A. Sökmen, H.A. Akpulat, (2003). Antioxidant and antimicrobial activity of the essential oil and methanol extracts of Achillea millefolium sub. sp. Millefolium Afan. (Asteraceae). J Ethno. Pharma. Col., 87: 215-220

Hoffman, D., (1996). The complete illustrated holistic herbal. Rockport, MA: Element Books Inc.

Fleming, T., (1998). PDR for herbal medicines. Montvale, NJ: medical Economics Company, Inc.

HawryłM., Skalicka-Woźniak K., Świeboda R., Niemiec M., Stępak K., Waksmundzka-Hajnos M., Hawrył A., Szymczak G.,(2015).GC-MS fingerprints of mint essential oils Open Chem., 2015; 13: 1326-1332.

Imai, H., K. Osawa, H. Yasuda, H. Hamashima, T. Arai and $\mathbf{M}$. Sasatsu, (2001). Inhibition by the essential oils of peppermint and spearmint of the growth of pathogenic bacteria, Microbios, 106: 31-39.

Mimica-Dukic, N., O. Gasic, G. Kite, R. Jancic, (1998). Essential oil of some populations of Mentha arvensis L. in Serbia and Montenegro. J. Essent. Oil Res. 10: 502-506.

Pereira, M. C., L. M. A. S. Costa, R. F. da. Silva, A. F. Fernandes, E. W. N. da. Fonseca and $R$. $H$. Piccoli, (2006). Inhibition of growth of fungi through utilization of essential oils of spices,

Ciencia. Agrotecnologia, 30(4):731-738.

Rodrigo, R., C. Bosco, (2006). Oxidative stress and protective effects of polyphenols: Comparative studies in human and rodent kidney. A review. Comparative Biochem. Physiol. Part $C$, 142:317-327. 